\title{
ONParkinson - Innovative mHealth to support the triad: patient, carer and health professional
}

\author{
Rui Neves Madeira ${ }^{1}$, Carla Mendes Pereira ${ }^{2}$, Sergiu Clipei $^{2}$ and Patrícia Macedo ${ }^{1}$ \\ ${ }^{1}$ Escola Superior de Tecnologia de Setúbal, IPS, Setúbal, Portugal \\ rui.madeira@estsetubal.ips.pt, patricia.macedo@estsetubal.ips.pt \\ ${ }^{2}$ Escola Superior de Saúde, IPS, Setúbal, Portugal \\ carla.pereira@ess.ips.pt, sergiu.c3@gmail.com
}

\begin{abstract}
The ONParkinson mHealth platform aims to empower an integrated assistance to support end-users of the triad "people with Parkinson's Disease, their carers and health professionals", promoting the self-management in Parkinson's disease. Therefore, ONParkinson is expected to optimize the communication between the triad users, helping them find relevant knowledge to support their clinical issues, as well as allowing the monitoring of patients daily routine and the recommendation for daily exercises. This mHealth solution was created and materialized after an initial study of the end-users' needs. This paper presents the usability study of the first version of the ONParkinson prototype. According to the usability tests' findings, ONParkinson was perceived by the triad users as easy to use, with functionalities well integrated, useful and attractive. Some recommendations were suggested to enhance its usability, users' satisfaction and continuance intentions.
\end{abstract}

Keywords. Parkinson's disease, mHealth, mobile computing, usability, selfmanagement.

\section{Introduction}

Mobile devices can be found everywhere around people, which makes them be seen as a ubiquitous entity, being almost universally connectable and appearing in almost everywhere. Accordingly, there is an emerging consumer-driven demand for a more personalised health system, and there is no question that the rapid evolution of the mobile application market became an important driver for personalisation in the health field. The concept of mHealth is changing how healthcare is delivered [1], with an increased support to the management of chronic diseases [2], such as Parkinson's disease (PD), which is recognised as the most common neurodegenerative disorder after Alzheimer's disease [3, 4], with a higher prevalence in Europe and Portugal [5]. Mobile phones and other networked devices offer a unique opportunity to engage remotely the people involved in managing PD, including both people with PD and health professionals, as well as carers/family.

Starting from a study of the needs of the triad "people with PD, their carers and health professionals", our multidisciplinary team proposed the development of an mHealth platform - ONParkinson - based on the empowerment of this triad to help both patients and carers to manage PD better [6]. In this paper, the usability study of the first version of the mHealth prototype is presented. 


\section{Background}

Mobile applications (apps) have been designed to support people with PD by providing, for instance, recommendations and instructions about home exercises. However, research findings of its effectiveness are limited. Most studies in this field applied to PD have investigated the use of apps for home-based monitoring and assessment of motor complications with data being used mainly by health professionals for clinical decision $[7,8]$. Moreover, more recent studies focused on a user-centred process for the design of apps present positive results. Indeed, findings indicated that people with PD were able to achieve high task completion rates on usability tests, showing that usercentred approaches can be efficient [9].

Furthermore, most of the health services and self-management tools provided have been centred on the person with PD and in supporting clinical decisions. Thus, apps have been developed in order to improve the patients' capabilities of self-management of the PD (e.g., the REMPARK system [9] and the mPower app [10]). However, the involvement of both people with PD and their carers has been highlighted as providing benefits to them [11]. The majority of people with PD live in the community and are cared for by family members, who are often referred to as 'informal' carers that play a vital role, providing social, physical and psychological support over an extended period. The impact of the disease on the lives of people with PD and their carers is wideranging, affecting daily living and altering roles. PD is a condition that becomes less predictable over time, with symptoms fluctuating rapidly within the day or week-byweek. The slowness of movement, rigidity, and tremor are often present and will impact on the person's ability to be active. Moreover, there are numerous 'non-motor' symptoms associated with PD, including anxiety, depression, fatigue, pain and sleep disturbance, which are associated with reduced health-related quality of life [3].

Thus, for both the patient and the carer, it is important to understand the disease and its progression in order to manage symptoms and find solutions for their daily challenges, as well as to maintain the communication with health professionals for an effective shared decision-making within the triad. This understanding and symptoms monitoring are expected to increase their ability for self-manage the disease over time, improve their quality of life, reduce carers strain and reduce hospitalization/visits. However, to the best of our knowledge, there are no solutions based on mobile apps in this field aiming to combine both patient and carer's support for a broader management approach of PD.

\section{ONParkinson}

The ONParkinson mHealth solution is a platform formerly known as Smoveen, in which a mobile app is the main interface to provide patients and carers with selfmanagement capabilities to help them feel empowered in their ability to find strategies in a more informed and collaborative way. The mobile device acts as the communication channel between the user and the system. It should remain with the user and it is essential that the user may be able to interact with it as many times as possible. The platform also intends to optimize therapy outside the clinical context with remote support from the health professionals, providing them with an exclusive Web interface. 


\subsection{The Mobile App}

The first prototype of this mHealth app was implemented in Java for the Android platform, taking into account that Android apps have the longest reach in the mass market, which give us the intended space to work closely with the ONParkinson's target audience. Although being created to support patients and carers with self-management capabilities within the triad, the "common user" type (user with no account) was considered in the app design. This type of user can install the app and use the open features to consult essential information about PD and ask open questions related to the pathology, without the need of being under the supervision of a health professional registered on the platform.

Considering that the goal of self-management technologies has been to quantify, track, and keep the condition under control [12], this app was designed to provide integrated ways to control the evolution of the disease. It allows the establishment of communication among the triad users, the management of daily tasks (medication and exercises program) and the privileged access to specific information about PD in a simple and natural manner [6]. The concept of ONParkinson has been tested in a first prototype that presents functionalities based on three main dimensions of intervention towards both the patient and the carer (Figure 1): Information, Calendar and Exercises.

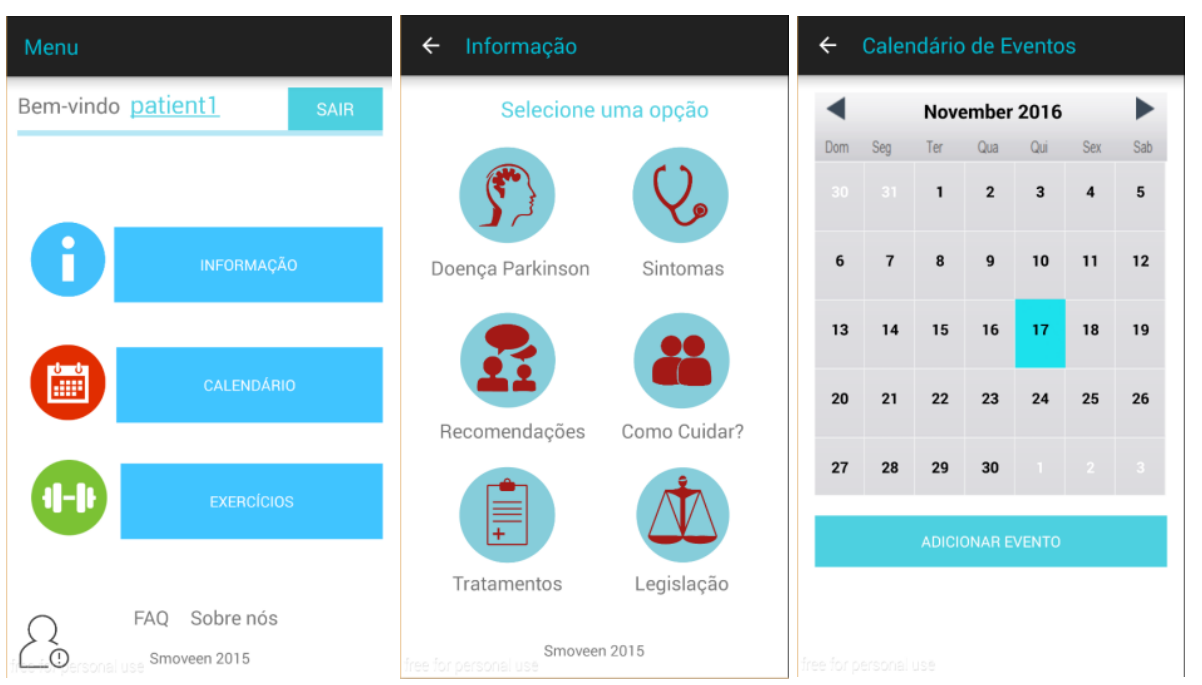

Fig. 1. ONParkinson screens: left) home menu; middle) information menu; right) calendar.

The Information module includes six essential categories from which are commonly asked questions related to PD, namely: "What is Parkinson's Disease?"; "Symptoms"; "Recommendations"; "Caring role"; "Treatments"; and "National legislation".

The Calendar interface presents events regarding medication prescript and exercises program. Usually, these events are inserted in the patient's calendar by the health professional, who use the Web interface to supervise patients' actions. These events cannot be altered either by the patient nor her/his carer(s). Nonetheless, as long as patients have autonomy, they can add events (e.g. medical appointments, treatment 
sessions, leisure activities or others) to the calendar, as well as can her/his carers, who can also supervise the patients' actions. This approach intends to make the ONParkinson mobile app more comprehensive and useful to the users. The app sends notifications to both the users, patient and carer, as reminders to take the medication or execute the scheduled exercises. This functionality intends to place both the patient and the carer at the centre of the decision, empowering them to manage PD in a more integrated way.

The Exercises program interface allows the patient, or the carer, to select generic exercises to follow and learn how to practice them (Figure 2, left image). Additionally, the user may have a program prescribed by the health professional, which will appear as an event in the calendar. When opening the program, the patient (or the carer in her/his behalf) starts by rating her/his perceived exertion (Borg Scale) (Figure 2, middle image) and recording the cardiac rate and blood pressure (optional step). Then, the exercises program will initiate, having three distinct phases: warm-up, training and cool down. The right image of Figure 2 illustrates a warm-up exercise. The session will end up with an evaluation of the perceived exertion, cardiac rate and blood pressure.

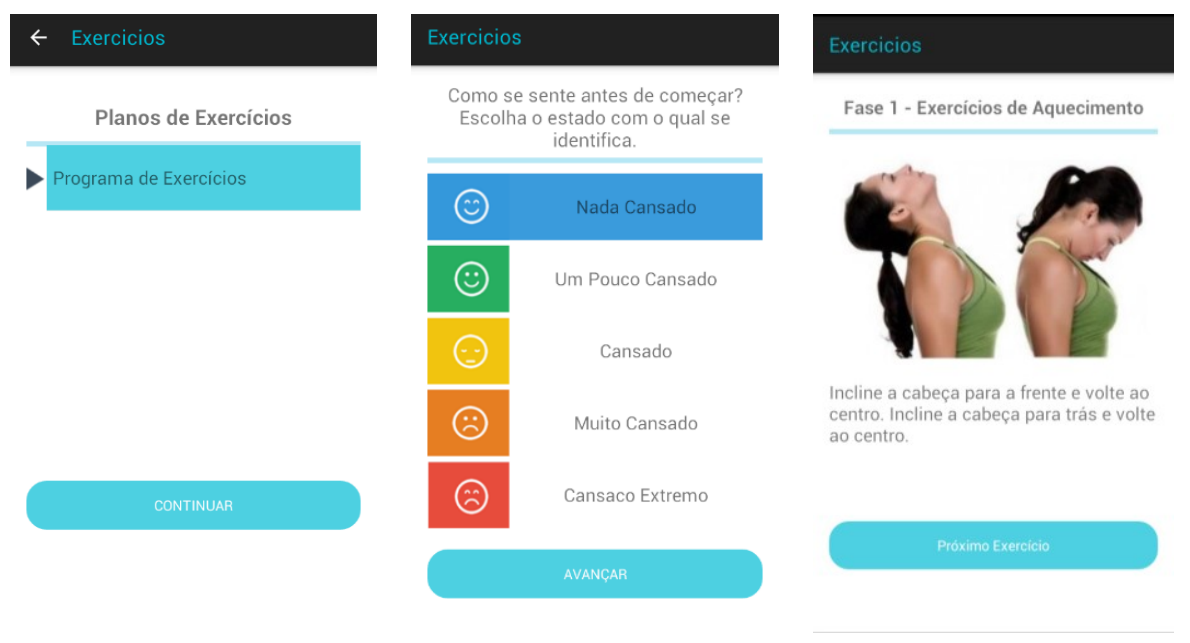

Fig. 2. ONParkinson screens: left) exercises programs; middle) mood selection; right) exercise.

\subsection{The Platform}

The platform's system includes a server that contains a central repository where all data are stored. The server manages all the requests from the ONParkinson app instances installed on the end-user's mobile devices, which are identified as clients of the system. All communications between users within the app are managed and synced by the server. The users do not need to be always connected to the Internet to use the app, but this will request connections periodically in order to do synchronizations with the server. The app connects to the server to obtain and store the required data for all users. There are specific synchronization moments to guarantee that all the information is 
always up-to-date, being coherent between the server's repository and the local database of the app's instance.

The platform integrates a Web app directed to the health professional, which works as a complement to the mHealth app. It is the main interface for the health professional since it can present more detailed information about her/his patients. The Web app integrates a more complete and interactive dashboard than the mobile interface, allowing better monitoring and remote support of the therapy outside the clinic context. An important feature of this Web app is an interface in which the health professional adds new therapeutic exercises to the platform and creates programs based on them towards her/his patients. Figure 3 illustrates the main components of the platform.

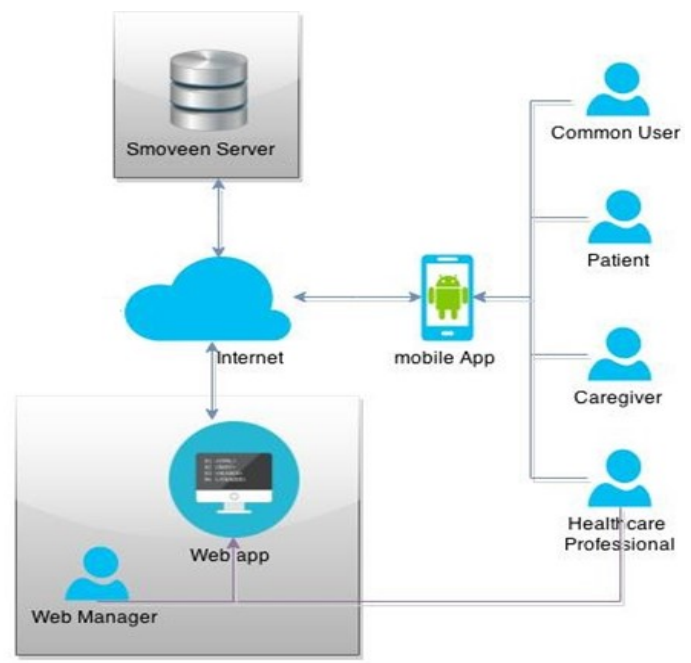

Fig. 3. The system architecture.

\section{$4 \quad$ User Study}

The ONParkinson R\&D team has being following an iterative design process. Therefore, until now, first the concept and then the mobile app prototype have been tested by different users at different times and for different purposes. A preliminary user study was conducted to validate the ONParkinson's concept and the potential needs of the triad users [6]. Results highlighted the importance of implementing an mHealth based platform to support a remote healthcare assistance, with most of participants identifying it as "extremely relevant" [6].

A first test round with triad users started as soon as the team got a functional prototype. We carried out user tests with the ONParkinson mobile prototype in order to evaluate the acceptance of the modules and functionalities included in this first version, besides the overall usability of the application. This study was important to assess if the mHealth solution was being developed in the intended direction. 


\subsection{Design}

The users testing conducted in this study comprised accomplishing tasks and post-test questionnaires. The ONParkinson team divided the tests in two parts, measuring the overall usability quality of the app using the European Portuguese version of the System Usability Scale (SUS) [13], as well the user satisfaction regarding the main modules (both parts using a seven-point Likert-type scale, which ranged from strongly disagree (1) to strongly agree (7)).

The user tests were conducted with a total of 14 participants from the Portuguese Parkinson Disease Association (literally Associação Portuguesa de Doentes de Parkinson - APDPk), including 5 people with PD (2 female; average age of $64+/-5.92$ ), 5 carers ( 1 female; average age of $66+/-15.34$ ), and 4 health professionals ( 2 female; 3 physiotherapists and 1 speech therapist). From these set groups, people with PD were the participants' group that reported a lower use of smartphones in their daily life ( 3 of the 5). On the other hand, only one carer did not use, and all health professionals were smartphones users. Figure 4 illustrates how the ONParkinson team conducted the usability tests with participants at the Association. A cared supervision was needed.
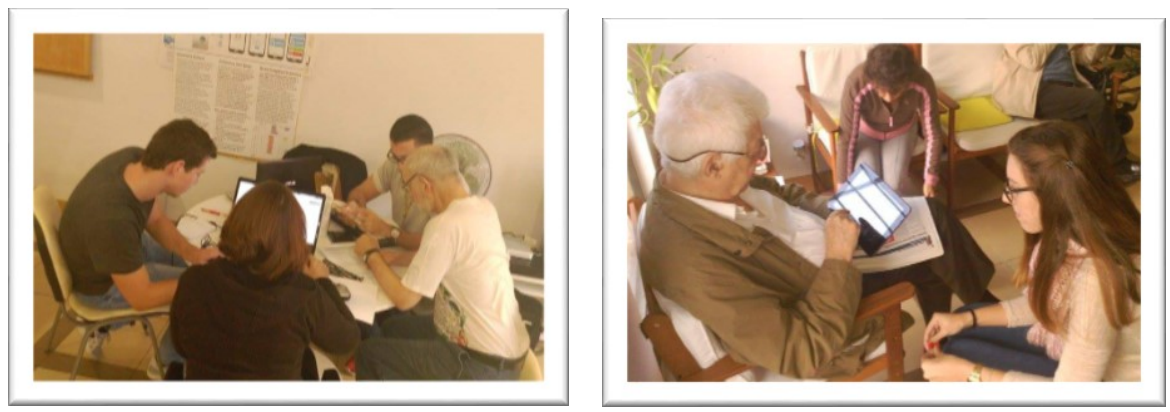

Fig. 4. Usability tests process: ONParkinson team with participants (patients and carers).

\subsection{Findings}

According to the first part of the tests, based on SUS, the ONParkinson app has proven to be easy to use (mean $=6.65 ; \mathrm{SD}=.53$ ) and with few inconsistencies in the system (mean=1.28; $\mathrm{SD}=.61)$. Most of the SUS statements were classified equally within the triad end-users. However, differences seemed to be found in the possibility of using the app frequently. People with PD answered positively (mean $=5.6 ; \mathrm{SD}=.89$ ), but lower than their carers (mean $=6.4 ; \mathrm{SD}=.89$ ) and health professionals $($ mean $=6.75 ; \mathrm{SD}=.50$ ), which may indicate the importance of a deeper understanding of their motivations and expectations for its use, and more specifically, in the context of the triad's interaction using the app. Table 1 shows the complete results obtained from the SUS questionnaire, which demonstrate that the usability evaluation was overall very positive.

For a first prototype, the SUS score was very high with a value of 84.4 out of 100 , meaning the ONParkinson mobile app obtains an A grade, which is the best possible. This grade also indicates that participants are more likely to be recommending the product to another potential end-user. These positive results, somewhat above the expectations, may be related to the way in which the participants' selection took place 
at APDPk. People who wanted to participate are possibly those who are most interested and predisposed to use new technologies and solutions based on mobile devices. Moreover, during the tests, several participants reported they wanted very much that the prototype would reach the final version in order to be able to use it on a daily basis. However, despite the very positive global results, the SUS scores of two participants were weaker since a person with PD obtained a value of 65.0 and a carer obtained only 55.0. We were expecting to obtain some scores like these two since we were dealing with people who could present obvious limitations, whether they were due to the disease or age, whose average was over 60 years.

Table 1. Results of the user tests' first part based on SUS.

\begin{tabular}{|c|c|c|c|c|}
\hline Statements & $\begin{array}{c}\text { People } \\
\text { with PD }\end{array}$ & Carers & $\begin{array}{c}\text { Health } \\
\text { professionals }\end{array}$ & TOTAL \\
\hline $\begin{array}{l}\text { S1: I think that I would like to use } \\
\text { ONParkinson frequently }\end{array}$ & $5,60 \pm 0,89$ & $6,40 \pm 0,89$ & $6,75 \pm 0,50$ & $6,25 \pm 0,76$ \\
\hline $\begin{array}{l}\text { S2: I found ONParkinson } \\
\text { unnecessarily complex }\end{array}$ & $2,40 \pm 1,52$ & $3,20 \pm 3,03$ & $2,50 \pm 1,00$ & $2,70 \pm 1,85$ \\
\hline $\begin{array}{l}\text { S3: I thought ONParkinson was easy } \\
\text { to use }\end{array}$ & $6,60 \pm 0,55$ & $6,60 \pm 0,55$ & $6,75 \pm 0,50$ & $6,65 \pm 0,53$ \\
\hline $\begin{array}{l}\text { S4: I think that I would need the } \\
\text { support of a technical person to be } \\
\text { able to use ONParkinson }\end{array}$ & $3,60 \pm 2,30$ & $2,20 \pm 1,30$ & $2,50 \pm 2,38$ & $2,77 \pm 1,99$ \\
\hline $\begin{array}{l}\text { S5: I found the various functions in } \\
\text { ONParkinson were well integrated }\end{array}$ & $6,40 \pm 0,55$ & $6,20 \pm 1,30$ & $6,25 \pm 0,50$ & $6,28 \pm 0,78$ \\
\hline $\begin{array}{l}\text { S6: I thought there was too much } \\
\text { inconsistency in ONParkinson }\end{array}$ & $1,40 \pm 0,89$ & $1,20 \pm 0,45$ & $1,25 \pm 0,50$ & $1,28 \pm 0,61$ \\
\hline $\begin{array}{l}\text { S7: I would imagine that most people } \\
\text { would learn to use ONParkinson very } \\
\text { quickly }\end{array}$ & $6,40 \pm 0,89$ & $5,00 \pm 2,45$ & $5,75 \pm 0,96$ & $5,72 \pm 1,43$ \\
\hline $\begin{array}{l}\text { S8: I found ONParkinson very } \\
\text { cumbersome to use }\end{array}$ & $1,40 \pm 0,55$ & $2,20 \pm 2,68$ & $1,00 \pm 0,00$ & $1,53 \pm 1,08$ \\
\hline $\begin{array}{l}\text { S9: I felt very confident using } \\
\text { ONParkinson }\end{array}$ & $5,80 \pm 1,30$ & $6,40 \pm 0,89$ & $6,25 \pm 0,50$ & $6,15 \pm 0,90$ \\
\hline $\begin{array}{l}\text { S10: I needed to learn a lot of things } \\
\text { before I could get going with } \\
\text { ONParkinson }\end{array}$ & $2,20 \pm 2,17$ & $1,60 \pm 1,34$ & $1,50 \pm 0,58$ & $1,77 \pm 1,36$ \\
\hline
\end{tabular}

With regard to the second part of the tests, Table 2 shows a summary of the results about three characteristics of the "app's image" (global design, logo, and font size) and the main modules/functionalities (Information, Exercises and Calendar), which were globally perceived as being well integrated. Moreover, the first two statements received the highest scores, which illustrates how much participants really liked the concept and image that is being followed by the ONParkinson development.

Additionally, users contributed with qualitative feedback and recommendations for improving the experience of the app. For instance, textual descriptions on the Information module were perceived as too long for some users, mainly for people with PD and carers. Health professionals recommended an increase of the number of exercises that may be selected from the ONParkinson's repository. 
Table 2. Results of the user tests' second part regarding user satisfaction with specific aspects.

\begin{tabular}{|c|c|c|c|c|}
\hline Statements & $\begin{array}{l}\text { People } \\
\text { with PD }\end{array}$ & Carers & $\begin{array}{c}\text { Health } \\
\text { professionals }\end{array}$ & TOTAL \\
\hline S1: The app has an attractive design & $6,50 \pm 0,58$ & $6,20 \pm 0,84$ & $6,50 \pm 0,58$ & $6,40 \pm 0,67$ \\
\hline S2: The logo is suitable for the app & $7,00 \pm 0,00$ & $5,60 \pm 1,52$ & $7,00 \pm 0,00$ & $6,53 \pm 0,51$ \\
\hline S3: Font size is appropriated & $6,50 \pm 0,58$ & $5,80 \pm 1,30$ & $6,50 \pm 0,58$ & $6,27 \pm 0,82$ \\
\hline $\begin{array}{l}\text { S4: The functionality "Information" } \\
\text { has useful and proper information }\end{array}$ & $6,25 \pm 0,50$ & $6,40 \pm 0,89$ & $6,25 \pm 0,50$ & $6,30 \pm 0,63$ \\
\hline $\begin{array}{l}\text { S5: It was easy to create and access to } \\
\text { the events in the "Calendar" }\end{array}$ & $6,50 \pm 0,58$ & $5,80 \pm 1,10$ & $6,50 \pm 0,58$ & $6,27 \pm 0,75$ \\
\hline $\begin{array}{l}\text { S6: The functionality "Exercises" is } \\
\text { easy to follow }\end{array}$ & $6,75 \pm 0,50$ & $6,20 \pm 0,45$ & $6,75 \pm 0,50$ & $6,57 \pm 0,48$ \\
\hline
\end{tabular}

\section{Conclusions and Further Work}

Based on the measured user experience, this study demonstrated that the ONParkinson development is on the right path, with a high acceptance by the potential end-users, and proposed recommendations for enhancing the usability of the app.

We will continue gathering feedback while developing the prototype, assessing each one of its modules with the end-users. As part of this ongoing process, we are selecting a group of end-users that should participate in all user tests. Improving the usability of the ONParkinson mobile app may enhance the user experience to engage mainly the patients and their carers.

Acknowledgments. We would like to thank the students Patricia Garcia, Daniel Costa and Natália Scerbacov for their participation in the development of the prototype and collaboration in the users testing at APDPk. We also wish to thank APDPk for providing the support needed for the testings with the potential end-users.

\section{References}

1. World Health Organization. mHealth. New horizons for health through mobile technologies. http://www.who.int/goe/publications/goe_mhealth_web.pdf (2011) Retrieved Sep 27, 2016.

2. Steinhubl, M.D., Muse, E.D., Topol, E.J. Can Mobile Health Technologies transform health care? The Journal of American Medical Association, 310 (22), 2395-6 (2013)

3. Kalia, L., Lang, A. 2015. Parkinson's disease. 386, 896-912, Lancet (2015)

4. Dorsey, E.R., Constantinescu, R., et al. Projected number of people with Parkinson disease in the most populous nations, 2005 through 2030. Neurology; 68, 384-86 (2007).

5. European Commission. 2015. Neurodegenerative Disorders. http://ec.europa.eu/health/major_chronic_diseases/diseases/brain_neurological Accessed 25th June 2015

6. Pereira, C., Macedo, P., Madeira, R. Mobile Integrated Assistance to Empower People Coping with Parkinson's Disease. ASSETS `15, 409-410. ACM (2015)

7. Pan, D., Dhall, R., Lieberman, A., Petitti, D.B. A Mobile Cloud-Based Parkinson's Disease Assessment System for Home-Based Monitoring. JMIR Mhealth Uhealth. 3(1), e29 (2015)

8. Patel, S., et al. Monitoring motor fluctuations in patients with Parkinson's disease using wearable sensors. IEEE Trans. Inf. Technol. Biomed. 13(6), 864-73 (2009) 
9. Barros, A.C., Cevada, J., Bayés, A., Alcaine, S., Mestre, B. User-centred design of a mobile self-management solution for Parkinson's disease. In Proc of 12th International Conference on Mobile and Ubiquitous Multimedia (MUM '13). Article 23, 10 pp. ACM (2013)

10.Bot, B., Suver, C., Neto, E.C., et al. The mPower study, Parkinson disease mobile data collected using ResearchKit. Scientific Data 3, 160011, 1-9 (2016)

11.Trend, P., Kaye, J., Gage, H., Owen, C., Wade, D. Short-term effectiveness of intensive multidisciplinary rehabilitation for people with Parkinson's disease and their carers. Clinical Rehabilitation 2002; 1 6: 717-725 (2002)

12.Nunes, F., Verdezoto, N., Fitzpatrick, G., Kyng, M., Grönvall, E., Storni, C. Self-Care Technologies in HCI: Trends, Tensions, and Opportunities. ACM Trans. Comput.-Hum. Interact. 22, 6, Article 33, 45 pages (2015)

13.Martins, A., Rosa, A. Queirós, A., Silva, A., Rocha, N. European Portuguese validation of the System Usability Scale (SUS). Procedia Computer Science. 67, 293-300 (2015) 